\title{
Survey Potensi Excess Power di Kabupaten Indragiri Hilir
}

\author{
AKBAR ALFA ${ }^{1}$, ROBERTA ZULFHI SURYA ${ }^{2}$ \\ 1Program Studi Teknik Sipil , Universitas Islam Indragiri, Riau \\ 2Program Studi Teknik Industri, Universitas Islam Indragiri, Riau \\ 1alfa.boyone@gmail.com, 2robertazulfhi@yahoo.co.id
}

\begin{abstract}
ABSTRAK
Energi Listrik merupakan komponen kunci untuk pengembangan daerah dan merupakan strategi yang akan berkelanjutan dengan dampak-dampak yang telah terbukti memberikan kontribusi besar pada pengembangan kesejahteraan masyarakat. Tingkat pemakaian energi sering digunakan sebagai salah satu indikator tingkat kemakmuran. Namun kebutuhan energi listrik hingga saat ini belum terpenuhi karena seringnya terjadi pemadaman dan rencahnya rasio elektrifikasi. Di Kabupaten Indragiri Hilir beroperasi sekitar 25 Perusahaan besar yang memiliki pembangkit listrik sendiri, baik itu menggunakan Tenaga Uap maupun Tenaga Diesel. Penelitian ini mengkaji potensi penerapan Excess Power surplus energi listrik yang dimiliki perusahaan untuk didistribusikan kepada konsumen melalui PLN. Sampel dari penelitian ini adalah 3 perusahaan besar yakni PT. Agro Sarimas Indonesia, PT. Kokonako Indonesia dan PT. Pulau Sambu Kuala Enok. Disamping itu juga mewawancarai keinginan masyarakat serta mengkaji regulasi terkait Excess Power. Hasil penelitian adalah potensi Excess Power adalah PT. Agro Sarimas Indonesia yang sedang membangun powerplan dan diharapkan beroperasi awal 2017. PT.ASI berpotensi excess power sebesar 5-6 MW. Setidaknya dapat membantu pemenuhan demand energi di Kecamatan Kempas. Selain itu surplus energi PT. Pulau Sampu Kuala Enok juga diharapkan mampu menutupi kekurangan pasokan energi listrik di Desa Tanah Merah dan Kelurahan Kuala Enok. Disaat swasta menyediakan tenaga listrik bagi kepentingan umum, tarif yang ditagih kepada konsumen diatur dalam pasal 41 ayat (2) UU Nomor 30 Tahun 2009 tentang Ketenagalistrikan untuk wilayah kabupaten Indragiri Hilir tarif harus disahkan oleh Bupati Indragiri Hilir.
\end{abstract}

Kata Kunci: Excess Power, Energi Listrik, Tarif.

\section{PENDAHULUAN}

Energi Listrik merupakan komponen kunci untuk pengembangan daerah dan merupakan strategi yang akan berkelanjutan dengan dampak-dampak yang telah terbukti memberikan kontribusi besar pada pengembangan kesejahteraan masyarakat. Tingkat pemakaian energi sering digunakan sebagai salah satu indikator tingkat kemakmuran. Tetapi kebutuhan energi listri hingga saat ini belum terpenuhi karena seringnya terjadi pemadaman dan rencahnya rasio elektrifikasi. Pembangunan daerah ini tidak dapat dilaksanakan oleh Pemerintah saja. Namun Integrasi antara seluruh stakeholder (Akademik, Swasta, dan Pemerintah) dalam pembangunan daerah perlu dipertimbangkan. Dikarenakan tantangan utama yang dihadapi adalah funding gaps antara kebutuhan biaya membangun daerah dengan terbatasnya kemampuan keuangan daerah untuk memenuhi kebutuhan tersebut. Maka oleh sebab itu muncul pertimbangan perlunya memperkuat kerjasama pemerintah dengan pihak swasta untuk melaksanakan pembangunan tersebut.

Ketersediaan energi listrik merupakan aspek yang sangat penting dan bahkan menjadi suatu parameter untuk mendukung keberhasilan pembangunan suatu daerah. Pengelolaan sumber daya energi listrik yang tepat dan terarah dengan jelas akan menjadikan potensi yang dimiliki suatu wilayah berkembang dan termanfaatkan secara optimal. Oleh karena itu, perencanaan dan pengelolaan energi secara umum termasuk di dalamnya adalah energi listrik perlu mendapatkan perhatian serius dari Pemerintah Daerah. Hal tersebut tentu juga seiring dan searah dengan peningkatan peran Pemerintah Daerah dalam mengelola sumber daya energi. Ketersediaan energi listrik yang memadai dan tepat sasaran akan memacu perkembangan pembangunan daerah seperti sektor industri, komersial, pelayanan publik dan bahkan kualitas hidup masyarakat dengan semakin banyaknya warga yang menikmati energi listrik. Kemudian secara langsung maupun tidak langsung, hal itu akan mempengaruhi pertumbuhan ekonomi dan tingkat kesejahteraan masyakarat.

Hingga saat ini masih terjadi kekurangan energi di Indragiri Hilir, khususnya energi listrik yang berakibat pada seringnya terjadi pemadaman listrik bergilir. Faktor penyebab terjadinya krisis tersebut adalah akibat gangguan pada mesin pada PLN Tembilahan (Riauone, 8 Januari 2015). Saat 


\section{Akbar Alfa, Roberta Zulfhi Surya}

ini masyarakat seringkali mengeluh seiring dengan dijalankannya kebijakan pemadaman listrik bergilir di hampir seluruh daerah yang di aliri listrik yang berasal dari PLN, terlebih sejak kebijakan 8 jam menyala dan 8 jam padam yang diumumkan PLN Tembilahan sejak pertengahan Maret 2015. Sedangkan untuk listrik desa yang mana energi listrik dikelola oleh desa menggunakan mesin Diesel hanya menyala pada pukul 17.30 hingga 24.00 dan dengan harga per-kWH yang tinggi sehingga masyarakat di pedalaman/pesisir terpencil tidak dapat beraktivitas menggunakan energi listrik secara penuh.

Di Kabupaten Indragiri Hilir beroperasi sekitar 25 Perusahaan besar yang memiliki pembangkit listrik sendiri, baik itu menggunakan Tenaga Uap maupun Tenaga Diesel. Penelitian ini mengkaji potensi penerapan Excess Power surplus energi listrik yang dimiliki perusahaan untuk didistribusikan kepada konsumen melalui PLN. Sampel dari penelitian ini adalah 3 perusahaan besar yakni PT. Agro Sarimas Indonesia, PT. Kokonako Indonesia dan PT. Pulau Sambu Kuala Enok. Disamping itu juga mewawancarai keinginan masyarakat serta mengkaji regulasi terkait Excess Power.

\section{METODE}

\section{Waktu dan Tempat Penelitian}

Penelitian dilakukan di Kabupaten Indragiri Hilir Provinsi Riau pada tanggal 1 Maret 2015 - 31 Desember 2015.

\section{Sampel}

Sampel dalam penelitian ini adalah sebagai berikut:

1. PT. Agro Sarimas Indonesia

2. PT. Kokonako Indonesia

3. PT. Pulau Sambu Kuala Enok

\section{Informan}

Informan yang berasal dari masyarakat adalah Hj. Murni (warga di sekitar PT. Pulau Sambu Kuala Enok)

\section{Data}

Data yang digunakan dalam penelitian ini adalah sebagai berikut:

1. Data Pembangkit Listrik milik Perusahaan dari Dinas Pertambangan dan Energi Kabupaten Indragiri Hilir Provinsi Riau;

2. Referensi hukum

3. Data primer hasil wawancara dengan masyarakat

4. Data primer hasil wawancara dengan perusahaan

\section{HASIL}

\section{Potensi Excess}

Sistem transmisi di wilayah Indragiri Hilir adalah off grid dan terpisah dari sistem transmisi Sumatera. Hal tersebut dikarenakan oleh wilayah Indragiri Hilir berkarakteristik terpisah-pisah antara satu wilaah dengan wilayah lain. Sebagian besar wilayah pedesaan terpisahkan oleh delta, selat maupun pesisir yang jaraknya sangat berjauhan. Hal tersebut menimbulkan ketidakmungkinan untuk dijadikan sistem interkoneksi dan bergabung dalam sistem sumatera.

Pengelolaan listrik yang dijalankan di PLN di beberapa wilayah sangat dirasakan dampak positifnya oleh masyarakat. namun akhir-akhir ini seringkali terjadi pemadaman bergilir akibat mesin rusak dan tingginya demand. Keberadaan Agro Industri (Kelapa dan CPO) dirasakan cukup berpotensi dalam mecari pemecahan kekurangan daya PLN. Hampir semua perusahaan 
tersebut memiliki pembangkit untuk memenuhi kebutuhan energinya, ada yang memakai cangkang sawit ada juga menggunakan batubara sebagai bahan bakar. Sebagian industriindustri ini surplus energi, seperti berita yang dirilis oleh media Bisnis.com. general manager PT.PLN wilayah riau menyebutkan keberadaan PT. Agro Sarimas Indonesia yang terletak di Sungai Gantang Indragiri Hilir akan sangat membantu pemenuhan demand, karena saat ini kami sudah CPA 1,2 MW, kami sangat terbuka untuk Sarimas Group / PT. Agro Sarimas Indonesia (PT.ASI) apabila berniat menjual surplus energi dari pembangkit baru.

Pada wawancara peneliti dengan Adi Tampubolon, ST General Affair PT. Agro Sarimas Indonesia pada tanggal 25 Maret 2015 sebagai berikut:

Kebutuhan normal saat ini PT. ISK/PT. ASI adalah 9-12 MW, masih defisit sekitar 0,7 MW. Kondisi exixting power plan kami secara teoritis mampu membangkitkan daya sebesar 8,3 MW dengan 2 pembangkit turbin batubara dan 3 Genset. Namun, saat ini sedang dilaksanakan pembangunan Powerplan bahan bakar batu bara dengan Kapasitas Besar yang di rencanakan selesai pada Januari 2016. Apabila powerplan tersebut selesai, kami berencana akan excess power sebesar 5-6 MW.

Selain itu, kami sedang merencanakan juga Powerplan dengan bahan bakar biogas dengan kapasaitas sebesar 2-3 MW. Sumber energinya adalah limbah industri dan akan berdampak pada pengurangan pencemaran lingkungan. Tentunya apabila kami surplus lagi, akan tetap kami excss power.

Berlainan dengan PT.ASI, peneliti mewawancarai PT. Kokonako Indonesia yang diwakili oleh Bapak Herman (Manager) dan Bapak M. Tarmizi (General Affair) pada tanggal 25 Maret 2015 sebagai berikut:

Powerplan PT. Kokonako Indonesia menggunakan bahan bakar biomassa, yakni shell atau yang dikenal dengan cangkang sawit. Daya mampu toeritis powerplan adalah 1,2MW, namun karena faktor "usia" powerplan yang sudah tua yang mengakibatkan daya maximalnya sekarang hanya 0,9 - 1MW saja. Sedangkan kebutuhan daya untuk operasional perusahaan sekitar 0,9 - 0,95 MW, jadi melihat kemampuan sekarang, kami belum bisa Excess power. Namun apabila pemerintah berniat serius exccess power dari Industri, nanti bisa kita bicarakan lebih lanjut, asal sesuai koridor hukum yang berlaku.

Pada hari yang sama peneliti mewawancarai PT. Pulau Sambu Kuala Enok (PT. PSK) yang diwakili oleh Bapak Sugiharto (Bagian Powerplan) dan Bapak H. Ruslan (General Affair) sebagai berikut:

Kemampuan maximal powerplan PT. PSK adalah $7 \mathrm{MW}$ dan kebutuhan normal 4-6MW dan surplus 0,5-1 MW. Namun saat ini sedang berlansung rencana pembangunan Coconut Wet Process (CWP) dengan kebutuhan energi $20 \mathrm{MW}$, sudah pasti PT. PKS defisit. Namun sejalan dengan dibutuhkan energi yang sangat besar tersebut, tentu ada rencana pembangunan powerplan juga. Kalau seandainya nanti kami surplus cukup besar dan pemerintah membutuhkan, kami akan excess power sejauh pihak top management menyetujui dan legalitasnya terpenuhi. Kondisi energi PT. PKS tidak jauh berbeda dengan PT. Pulau Sambu Guntung dan PT. Pulau Sambu Pulau Burungdengan kapasitas pembangkit sebesar 7 MW dan kebutuhan 4-6,5 MW sehingga surplusnya sangat kecil.

Pada kesempatan lain, peneliti mengunjungi PT. Putra Keritang Sawit (PT. PKS) yang berada di Kecamatan Kemuning pada tanggal 14 Agustus 2015. Fenomena menarik peneliti temukan di PT.PKS sebagai berikut:

PT. PKS mensupply energi listrik untuk 160 KK yang berada di wilayah RT.1 Desa Keritang Hulu dengan biaya subsidi perusahaan. Biaya subsidi tersebut dianggarkan dalam CSR Perusahaan

\section{Respon Masyarakat}

Pada tanggal 2 Oktober 2015 peneliti mewawancarai warga Desa Tanah Merah yang kebetulan berada di ring 1 PT. Pulau Sambu Kuala Enok, yaitu ibu Hj. Murni Nasrun. seperti pada kasus berikut ini:

Daerah kami ini terkenal dengan kemajuan industrinya, namun tidak sejalan dengan keadaan listrik daerah kami. sebelum bulan maret 2015, keadaan listrik disini sangat memprihatinkan. Pemadaman bergiliran dan tidak tentu jadwalnya. Yang jelas sering mati dari pada menyala. Kabarnya karena mesin listrik rusak. Dulu pernah ada isu PT. Sambu akan menjual listriknya melalui PLN, kami dari masyarakat sangat mengharapkan itu terealisasi. 
Wawancara di atas menyebutkan rusaknya mesin Pembangkit milik BUMN seringkali membuat kebutuhan listrik masyarakat tidak terpenuhi dan masyarakat berharap peran serta industri untuk menerangi daerah Indragiri Hilir ini. Ekspektasi masyarakat yang tinggi kepada masyarakat untuk memenuhi kebutuhan listrik sangat tinggi. Masyarakat sangat mengharapkan excess power karena akan memenuhi kebutuhan energi listrik konsumen.

\section{Penentuan Tarif}

Disaat swasta menyediakan tenaga listrik bagi kepentingan umum, tarif yang ditagih kepada konsumen diatur dalam pasal 41 ayat (2) UU Nomor 30 Tahun 2009 tentang Ketenagalistrikan untuk wilayah kabupaten Indragiri Hilir tarif harus disahkan oleh Bupati Indragiri Hilir (Pradana, 2013). Adapun tarif yang diatur harus memenuhi kriteria sebagai berikut:

a. Keseimbangan kepentingan nasional, daerah, konsumen, dan pelaku usaha penyedia tenaga listrik

b. Kepentingan dan kemampuan masyarakat

c. Kaidah industri dan niaga yangsehat

d. Biaya pokok penyediaan tenaga listrik

e. Efisiensi perusahaan

f. Skala pengusahaan dan interkoneksi sistem

g. Tersedianya sumberdana investasi

Pasal 23 ayat (3) Undang-undang Nomor 30 Tahun 2009 tentang Ketenagalistrikan junto Pasal 31 ayat (1) Peraturan Pemerintah Nomor 14 Tahun 2012 tentang Kegiatan Usaha Penyediaan Tenaga Listrik membuka kesempatan bagi pemegang Izin Usaha Ketenagalistrikan untuk kepentingan sendiri (IUKS) dalam hal ini Swasta untuk menjual kelebihan tenaganya kepada Pemengan Izin Usaha Penyediaan Tenaga Listrik untuk Kepentingan Umum (IUPTL) dalam hal ini PT.PLN atau lansung menjual surplus daya tersebut kepada masyarakat apabila wilayahnya belum terjangkau oleh pemegang IUPTL atau dalam hal ini PT.PLN. Proses penjualan tersebut dikenal dengan Excess Power (Pradana, 2013).

Peraturan Menteri ESDM Nomor 4 Tahun 2012 tentang Harga Pembelian Tenaga Listrik oleh PT PLN (Persero) dari Pembangkit Tenaga Listrik yang Menggunakan Energi Terbarukan Skala Kecil dan Menengah atau Kelebihan Tenaga Listrik menyatakan bahwa penjualan Excess Power dapat lebih besar dari tenaga listrik yang dipakai sendiri dan sesuai dengan kondisi/kebutuhan sistem ketenagalistrikan setempat.

\section{PENUTUP}

1. Keputusan Presiden Nomor 37 tahun 1992 tentang Usaha Penyediaan Tenaga Listrik Oleh Swasta menerangkan bahwa pintu privatisasi penyediaan tenaga listrik untuk kepentingan umum memberi kesempatan bagi swasta untuk berpartisipasi dalam kegiatan penyediaan tenaga listrik tersebut. Hal tersebut diperkuat lagi dengan Pasal 11 Undang-Undang Nomor 30 Tahun 2009 tentang Ketenagalistrikan. Undang-Undang Nomor 30 Tahun 2009 tentang Ketenagalistrikan membuka kesempatan kepada pihak swasta untuk dapat menjual secara lansung tenaga listrik ke Konsumen ataupun menjual ke PLN lalu PLN mendistribusikan kepada konsumen. Ada dua jalan untuk swasta apabila berniat menjual listriknya kepada masyarakat. yang pertama berdasarkan pasal 4 ayat 6 Permen ESDM nomor 10 tanun 2005 tentang tatacara perizinan usaha ketenagalistrikan untuk lintas provinsi atau terhubung dengan transmisi nasional. Pihak swasta hanya diperbolehkan menyelenggarakan penjualan daya kepada PT. PLN sebagai pemegang Izin Usaha Penyediaan Tenaga Listrik Nasional (IUPTL) dengan cara pihak swasta mengajukan penawaran kepada PLN dan persetujuan mentri. Kerjasama ini akan dituangkan dalam bentuk perjanjian jual-beli tenaga listrik atau Power Purchase Agreement (PPA) atau yang dikenal dengan Excess Power. Sesuai dengan hasil penelitian di lapangan, yang saat ini diharapkan berpotensi Excess Power adalah PT. Agro Sarimas Indonesia yang sedang membangun powerplan dan diharapkan beroperasi awal 2017. PT.ASI berpotensi excess power sebesar 5-6 MW. Setidaknya dapat membantu pemenuhan demand energi di Kecamatan Kempas. Selain itu surplus energi PT. Pulau Sampu Kuala Enok juga diharapkan mampu menutupi kekurangan pasokan energi listrik di Desa Tanah Merah dan Kelurahan 
Kuala Enok. Disaat swasta menyediakan tenaga listrik bagi kepentingan umum, tarif yang ditagih kepada konsumen diatur dalam pasal 41 ayat (2) UU Nomor 30 Tahun 2009 tentang Ketenagalistrikan untuk wilayah kabupaten Indragiri Hilir tarif harus disahkan oleh Bupati Indragiri Hilir.

2. Pasal 23 ayat (3) Undang-undang Nomor 30 Tahun 2009 tentang Ketenagalistrikan junto Pasal 31 ayat (1) Peraturan Pemerintah Nomor 14 Tahun 2012 tentang Kegiatan Usaha Penyediaan Tenaga Listrik membuka kesempatan bagi pemegang Izin Usaha Ketenagalistrikan untuk kepentingan sendiri (IUKS) dalam hal ini Swasta untuk menjual kelebihan tenaganya kepada Pemengan Izin Usaha Penyediaan Tenaga Listrik untuk Kepentingan Umum (IUPTL) dalam hal ini PT.PLN atau lansung menjual surplus daya tersebut kepada masyarakat apabila wilayahnya belum terjangkau oleh pemegang IUPTL atau dalam hal ini PT.PLN. Proses penjualan tersebut dikenal dengan Excess Power. Dalam hal ini PT. Pulau Sambu Kuala Enok dan PT. Agro Sarimas Indonesia berpotensi dijadikan rekan karena memiliki daya berlebih.

\section{DAFTAR PUSTAKA}

Riauone.com, Pemadaman listrik di Tembilahan, edisi 8 Januari 2015.

Safta Ekatama Consultant, Kajian Potensi Penerapan Kerjasama Pemerintah dan Swasta Dalam Penyediaan Tenaga Listrik di Kabupaten Indragiri Hilir [Laporan Kajian], Bappeda Inhil, Tembilahan, 2015

Ristyo Pradana, 2013. Prosedur Perizinan Penjualan Tenaga Listrik oleh Swasta. www.hukumonline.com

Ristyo Pradana, 2013. Izin Penjuala Kelebihan Tenaga (Excess Power) . www.hukumonline.com. 